Saudi Journal of Biomedical Research

Abbreviated Key Title: Saudi J Biomed Res ISSN 2518-3214 (Print) |ISSN 2518-3222 (Online)

\title{
Outcome of Open Reduction and Internal Fixation through Anterior Approach in Failed Closed Reduction of Supracondylar Humerus Fracture in Children
}

\author{
Indrajit Munda ${ }^{1}$, Pradip Kumar Ghosh ${ }^{2 *}$, Soudip Sinha ${ }^{3}$, Asish Kumar ${ }^{4}$, Debdutta Chatterjee ${ }^{5}$, Arijit Saha ${ }^{4}$ \\ ${ }^{1}$ Senior Resident, Department of Orthopedics, IPGMER, 244, Acharya Jagadish Chandra Bose Rd, Bhowanipore, Kolkata, West Bengal 700020 \\ ${ }^{2}$ Associate Professor, Department of Orthopedics, Burdwan Medical College and Hospital, Opp. Shyam Sayer, Khosbagan, Bardhaman, West Bengal \\ 713104, India \\ ${ }^{3}$ Assistant Professor, Department of Orthopedics, Coochbehar Government Medical College, Coochbehar, West Bengal 713104, India \\ ${ }^{4}$ Post Graduate Trainee, Department of Orthopedics, Burdwan Medical College and Hospital, Opp. Shyam Sayer, Khosbagan, Bardhaman, West Bengal \\ 713104, India \\ ${ }^{5}$ Professor, Department of Orthopedics, Burdwan Medical College and Hospital, Opp. Shyam Sayer, Khosbagan, Bardhaman, West Bengal 713104, \\ India
}

DOI: $10.36348 /$ sjbr.2020.v05i02.003

| Received: 16.02.2020 | Accepted: 24.02.2020 | Published: 27.02.2020

*Corresponding author: Pradip Kumar Ghosh

\section{Abstract}

Supracondylar fractures are a common entity among the pediatric age group and have been managed conservatively as well as operatively in various setups. In tertiary care setups, however, delayed presentation or failed closed reduction has posed a considerable challenge. Literature is few for anterior approach as it is a relatively new technique, but the outcomes were found to be satisfactory; it is also a safe approach. The present institution based, longitudinal, prospective study included 43 patients with Gartland type II/III fracture, aged 4-12 years attending the Orthopedics department within 2 weeks of fracture. 2 attempts of closed reduction after manipulation had failed in all patients. Open reduction and internal fixation was performed with $\mathrm{K}$-wire through anterior cubital approach. Mayo Elbow Performance Score was used to assess functional outcome at 6 weeks, 3months and 6 months. At 6 months of follow up 55.8\% of patients had excellent functional outcome and $41.9 \%$ patients had good outcome. Anterior approach is thus a viable alternative that can be explored further in cases of delayed presentation and failed reduction of supracondylar fractures in the pediatric patients.

Keywords: Supracondylar humerus fracture, children, anterior approach.

Copyright @ 2020: This is an open-access article distributed under the terms of the Creative Commons Attribution license which permits unrestricted use, distribution, and reproduction in any medium for non-commercial use (NonCommercial, or CC-BY-NC) provided the original author and source are credited.

\section{INTRODUCTION}

Supracondylar fractures of the humerus (SFH) account for $3 \%$ to $18 \%$ of all fractures in children [1]. SFH the most frequent fracture in children before the age of seven [2]. Ischemia of muscle and injury to nerve is the most serious complication of the injury [3]. Injury to any of the three major nerves around the elbow occurs in $6 \%$ to $16 \%$ of cases [4]. Cubitus varus is the most frequent problem with a mean incidence of $30 \%$ in the series reviewed by Smith [5]. Prevention of complications by careful clinical and radiological evaluation during initial treatment of the supracondylar fracture should be done [6]. Thus, the first step towards management of SFH is careful assessment of the fracture, taking into account the different factors that may modify the outcome, to minimize sequelae and complications.
Given these plethora of complications, it is not surprising that SFH management is also varied, and this has been studied in many ways by different researchers, with varying outcome and no single or unanimous decision regarding the best approach to fulfill all needs or to prevent all complications. A variety of methods of treatment for displaced fractures has been recommended including closed reduction and immobilization [7], closed reduction and posterior intrafocal pinning [8], closed reduction and lateral external fixation [9], traction by various methods [10] and closed [11] or open reduction [12] stabilised by Kirschner (K-) wires. These options display that the treatment goal in displaced supracondylar humerus fractures in children is anatomic reduction; if an anatomic reduction cannot be achieved with closed reduction, open reduction is indicated, and this can be done without an increased risk of complications [13]. 
Walmsley et al found that delay increases the need for open reduction of type-III supracondylar fractures of the humerus [14]. The commonly accepted treatment of displaced supracondylar fractures of the humerus in children is fracture reduction and percutaneous pin fixation; however, there is controversy about the optimal placement of the pins. A crossed-pin configuration is believed to be mechanically more stable than lateral pins alone; however, the ulnar nerve can be injured with the use of a medial pin [15]. In a 10-year follow-up study of children with SFH, Dunlop's method with skin traction was followed by minimal loss of elbow motion, less deformity, and no vascular complications [16].

So, we hypothesized that pediatric cases of SFH, who could not be managed by closed reduction or presented to the authors late, might be managed by open reduction and internal fixation via anterior approach.

\section{MATERIALS AND METHODS}

This study was an institution-based longitudinal, prospective study conducted for 14 months in the Department of Orthopedics in a tertiary care hospital in West Bengal. The study was approved by the local ethical committee and all patients gave their informed consent to take part in this investigation. The present study included 43 patients aged 4-12 years with Gartland type II/III fracture, attending the Orthopedics department within 2 weeks of fracture. 2 attempts of closed reduction after manipulation had failed in all patients. No other associated injuries were present. Complete history, physical and radiological examination (X Ray elbow- AP and lateral) of all cases were undertaken. Exclusion criteria included subjects who had Gartland type I fracture, age $<4$ or $>12$ years and attending the Orthopedics department after 2 weeks of fracture. After proper pre-op investigation and preanesthetic check-up, open reduction and internal fixation was performed with $\mathrm{K}$-wire through anterior cubital approach. After post-operative management, follow up was done at 6 weeks, 3 months and 6 months.

Mayo Elbow Performance Score (MEPS) was used to test the limitations of the elbow during activities of daily living. This specific test uses 4 subscales: Pain, Range/arc of motion, Stability and Function.

\begin{tabular}{llrc}
\multicolumn{2}{c}{ Table-1: Mayo Elbow } & Performance Score \\
Function & Definition & Points & Score classification \\
\hline Pain & None & 45 & Excellent $>90$ \\
& Mild & 30 & \\
& Moderate & 15 & \\
& Severe & 0 & \\
Motion & Arc $>100$ & 20 & Good, 75-89 \\
& Arc 50-100 & 15 & \\
& Arc $<50$ & 5 & \\
Stability & Stable & 10 & Fair, 60-74 \\
& Moderate instability & 5 & \\
& Gross instability & 0 & \\
Function & Comb hair & 5 & Poor $<60$ \\
& Feed & 5 & \\
& Hygiene & 5 & \\
Total & Shirt & 5 & \\
& Shoe & 5 &
\end{tabular}

\section{RESULTS}

There were 26 males and 17 females and the mean age was 6 years 2 months. The right limb was affected in 31 cases and left limb in 12 cases. Mean interval from injury to operation was 8 days.
Complications- 1 patient had temporary vascular insufficiency, which resolved after conservative management. 4 patients developed cubitus varus and 1 patient had median nerve injury which resolved partly.

Table-2: Clinical grading of patients at follow up (using MEPS)

\begin{tabular}{|l|l|l|l|l|l|}
\hline Follow up at & Excellent & Good & Fair & Poor & Total \\
\hline 6 weeks & 0 & 17 & 18 & 8 & 43 \\
\hline 3 months & 14 & 24 & 4 & 1 & 43 \\
\hline 6 months & 24 & 18 & 1 & 0 & 43 \\
\hline
\end{tabular}

At 6 months of follow up 55.8\% of patients had excellent functional outcome and $41.9 \%$ patients had good outcome according to MEPS.
Goals in the treatment of pediatric supracondylar humerus fractures are full recovery of elbow movements, achieving normal cosmetic view of elbow and protecting the patient from neurovascular complications that may occur. Peak incidence for $\mathrm{SFH}$ has been reported to be between the ages of 5 and 7

\section{DISCUSSION}


years [17]. In the present study, the mean age was 6 years 2 months. SFH is commoner in boys than girls [18], as also found in the present study. Supracondylar humerus fractures in children are frequently associated with various complications such as neurovascular deficit and compartment syndrome. In total, $7 \%$ to $16.1 \%$ neurological injuries are reported in the literature [19]. 1 case of median nerve involvement was noted in our study. This patients with neurological deficit was operated after 24 hours. A bonesetter had intervened in this case before hospital admission. Bonesetters intervene frequently in our society, and major complications may occur in the patients [20]. The patient intervened by a bonesetter was followed for one week due to edema and nerve injury. In the follow-up of this patient, $10^{\circ}$ flexion loss deformity was observed which was later corrected.

Closed reduction and percutaneous pinning have been accepted as the gold standard by many authors [11]. If close reduction cannot be achieved, open reduction should be preferred in serious displaced fractures, flexion-type fractures, nerve injuries after closed reduction, open fractures requiring irrigation and debridement, in posterolaterally displaced fractures with a high risk of neurovascular injury [21]. On the other hand, Kazimoglu et al compared primarily open reduction and internal fixation versus closed reduction and percutaneous cross-pinning of Gartland type 3 extension supracondylar fractures in children. The study performed at two different centres included 80 cases. They reported that according to Flynn's criteria [22], the outcomes of the open and closed reduction groups were not statistically significant. In conclusion, they say that closed reduction showed no superiority over open reduction [23]. Oh et al found that selective open reduction for displaced supracondylar fractures of the distal humerus produced as good results as closed reduction [24]. In our study, the patients were treated only with surgery. We observed $55.8 \%$ excellent and $41.9 \%$ good result for functional outcome after 6 months of follow up (Table-1).

With respect to various approaches, the authors believe that the medial approach prevents iatrogenic ulnar nerve injuries, it gives a good vision ensuring the restoration of the medial column, and it causes the least incisional scar; the lateral approach is more secure because it is away from the neurovascular structures; the anterior approach is better in the assessment of the joint and neurovascular structures; the posterior approach is better than other approaches in manipulation of fracture fragments. Gennari et al., [25] reported that although the anterior approach is more technically demanding, it gives better functional results. Ersan et al., [20] reported that a total of 46 patients were operated through anterior and 38 through lateral approach. According to Flynn's criteria [22], results were excellent in 19 , good in 18 , and fair in one in the lateral incision group, whereas in the anterior incision group, excellent results were obtained in 31 patients and good results in 15 of them. The authors say that when open reduction is needed in pediatric supracondylar fractures, anterior incision offers the advantage of a small scar and easy access to structures that might be injured between the fractured fragments. In the present study through anterior approach, at final follow up 24 of the patients had excellent results, 18 of them had good results and 1 patient had fair result at functional assessment using MEPS (Table-2).

As stated earlier, cubitus varus is the most frequent problem with a mean incidence of $30 \%$ in the series reviewed by Smith [5]. Surgical intervention decreases the rate of varus deformity. There were 4 cubitus varus cases $(9.3 \%)$ in our study group.

The present study was not without its limitations. The sample size was less; larger sample size will definitely have more reliable results. Duration of study was limited to approximately 14 months; late complication can arise at longer follow up period. The study was only an institutional based observational study, no comparison were made. Observer variation of clinical, radiological and surgical result was a limitation in spite of standardization of assessment methods.

Despite these limitations, the authors believe that data from the study might be of help in further research.

\section{CONCLUSION}

Anterior approach is a viable alternative that can be explored further in cases of delayed presentation and failed reduction of SFH in the pediatric patients. More studies with larger number of patients and less limitations should be carried out to validate the data from the present study, for better management of $\mathrm{SFH}$ in children.

Conflict of Interest: Nil

Financial Support: Nil

Acknowledgements: Nil

\section{REFERENCES}

1. Ramachandran, M., Skaggs, D. L., Crawford, H. A., Eastwood, D. M., Lalonde, F. D., Vitale, M. G., ... \& Kay, R. M. (2008). Delaying treatment of supracondylar fractures in children: has the pendulum swung too far?. The Journal of bone and joint surgery. British volume,90(9), 12281233.

2. Cheng, J. C., \& Shen, W. Y. (1993). Limb fracture pattern in different pediatric age groups: a study of 3,350 children. Journal of orthopaedic trauma, 7(1), 15-22.

3. Blakey, C. M., Biant, L. C., \& Birch, R. (2009). Ischaemia and the pink, pulseless hand complicating supracondylar fractures of the humerus in childhood: long-term follow-up. The 
Journal of bone and joint surgery. British volume, 91(11), 1487-1492.

4. Cramer, K. E., Green, N. E., \& Devito, D. P. (1993). Incidence of anterior interosseous nerve palsy in supracondylar humerus fractures in children. Journal of pediatric orthopedics, 13(4), 502-505.

5. Smith, L. (1960). Deformity following supracondylar fractures of the humerus. JBJS, 42(2), 235-252.

6. Labelle, H., Bunnell, W. P., Duhaime, M., \& Poitras, B. (1982). Cubitus varus deformity following supracondylar fractures of the humerus in children. Journal of pediatric orthopedics, 2(5), 539-546.

7. Hadlow, A. T., Devane, P., \& Nicol, R. O. (1996). A selective treatment approach to supracondylar fracture of the humerus in children. Journal of Pediatric Orthopaedics, 16(1), 104-106.

8. Fahmy, M. A. L., Hatata, M. Z., \& Al-Seesi, H. (2009). Posterior intrafocal pinning for extensiontype supracondylar fractures of the humerus in children. The Journal of bone and joint surgery. British volume, 91(9), 1232-1236.

9. Nacht, J. L., Ecker, M. L., Chung, S. M., Lotke, P. A., \& Das, M. (1983). Supracondylar fractures of the humerus in children treated by closed reduction and percutaneous pinning. Clinical orthopaedics and related research, (177), 203209.

10. Piggot, J., Graham, H. K., \& McCoy, G. F. (1986). Supracondylar fractures of the humerus in children. Treatment by straight lateral traction. The Journal of bone and joint surgery. British volume, 68(4), 577-583.

11. Mehserle, W. L., \& Meehan, P. L. (1991). Treatment of the displaced supracondylar fracture of the humerus (type III) with closed reduction and percutaneous cross-pin fixation. Journal of pediatric orthopedics, 11(6), 705-711.

12. Furrer, M., Mark, G., \& Rüedi, T. (1991). Management of displaced supracondylar fractures of the humerus in children. Injury, 22(4), 259-262.

13. Cramer, K. E., Devito, D. P., \& Green, N. E. (1992). Comparison of closed reduction and percutaneous pinning versus open reduction and percutaneous pinning in displaced supracondylar fractures of the humerus in children. Journal of orthopaedic trauma, 6(4), 407-412.

14. Walmsley, P. J., Kelly, M. B., Robb, J. E., Annan, I. H., \& Porter, D. E. (2006). Delay increases the need for open reduction of type-III supracondylar fractures of the humerus. The Journal of bone and joint surgery. British volume, 88(4), 528-530.

15. Skaggs, D. L., Hale, J. M., Bassett, J., Kaminsky, C., Kay, R. M., \& Tolo, V. T. (2001). Operative treatment of supracondylar fractures of the humerus in children: the consequences of pin placement. JBJS, 83(5), 735-740.

16. Mitchell, W. J., \& Adams, J. P. (1961). Supracondylar fractures of the humerus in children: a ten-year review. JAMA, 175(7), 573577.

17. Yousri, T., Tarassoli, P., Whitehouse, M., Monsell, F., \& Khan, W. S. (2012). Systematic review of randomized controlled trials comparing efficacy of crossed versus lateral K-wire fixation in extension type Gartland type III supracondylar fractures of the humerus in children. Ortop Traumatol Rehabil, 14(5), 397-405.

18. Mazda, K., Boggione, C., Fitoussi, F., \& Pennecot, G. F. (2001). Systematic pinning of displaced extension-type supracondylar fractures of the humerus in children: a prospective study of 116 consecutive patients. The Journal of bone and joint surgery. British volume, 83(6), 888-893.

19. Erdil, M., Imren, Y., Ceylan, H. H., Bilsel, K., \& Tuncay, İ. (2012). Multiple neural injuries in a pediatric supracondylar humerus fracture. J Clin Exp Invest, 3(3), 438-42.

20. Ersan, O., Gonen, E., Ilhan, R. D., Boysan, E., \& Ates, Y. (2012). Comparison of anterior and lateral approaches in the treatment of extensiontype supracondylar hume rus fractures in children. Journal of Pediatric Orthopaedics $B, 21(2), 121-126$.

21. Millis, M. B., Smger, I. J., \& Hail, J. E. (1984). Supracondylar fractures of the humerus in children. Clin Orthop. 188:90-97.

22. Flynn, J. C., Matthews, J. G., \& Benoit, R. L. (1974). Blind Pinning of Displaced Supracondylar Fractures of the Humerus in Children: Sixteen Years'experience With Long-Term FollowUp. JBJS, 56(2), 263-272.

23. Kazimoglu, C., Çetin, M., Şener, M., Aguş, H., \& Kalanderer, Ö. (2009). Operative management of type III extension supracondylar fractures in children. International orthopaedics, 33(4), 10891094.

24. Oh, C. W., Park, B. C., Kim, P. T., Park, I. H., Kyung, H. S., \& Ihn, J. C. (2003). Completely displaced supracondylar humerus fractures in children: results of open reduction versus closed reduction. Journal of orthopaedic science, 8(2), 137-141.

25. Gennari, J. M., Merrot, T., Piclet, B., \& Bergoin, M. (1998). Anterior approach versus posterior approach to surgical treatment of children's supracondylar fractures: comparative study of thirty cases in each series. Journal of pediatric orthopedics. Part B, 7(4), 307-313. 